\title{
TRANSUNGUAL PERMEATION OF THE VORICONAZOLE NAIL LACQUER AGAINST TRICHOPHYTON RUBRUM
}

\author{
*Tandel Amruta ${ }^{1}$, Agrawal Surendra ${ }^{2}$, Wankhede Shaijesh ${ }^{3}$ \\ ${ }^{1}$ Department of Pharmacology, Narsee Monjee Institute of Management Studies, School of Pharmacy \& Technology Management, Shirpur - \\ 425405, Maharashtra, India. \\ ${ }^{2}$ Department of Pharmaceutics, Narsee Monjee Institute of Management Studies, School of Pharmacy \& Technology Management, Shirpur - \\ 425405, Maharashtra, India. \\ ${ }^{3}$ Department of Anatomy, Physiology and Pharmacology, Oriental college of Pharmacy, Navi Mumbai, Maharashtra, India \\ *Corresponding author's Email: amruta tandel@hotmail.com Ph: 91-9967835838, 91-9967522305, \\ Received 09 Dec 2011; Revised 05 Jan 2012; Accepted 05 Jan 2012, Available online 20 Jan 2012
}

\begin{abstract}
The oral therapies encounter side effects and topical therapies for nail diseases are limited by poor permeability of nail plate. An optimal penetration enhancer would improve drug delivery through nail plate facilitating new possibilities for treating neighboring target sites if the systemic circulation is reached. The purpose of study was to determine amount of voriconazole permeating through the nail plate from the nail lacquer formulation containing permeation enhancer and to demonstrate its susceptibility to the onchomycotic dermatophyte. The permeability studies were performed on avulsed human cadaver nail plates using modified Franz diffusion apparatus containing phosphate buffer saline in the acceptor chamber. The amount of Voriconazole permeated was quantitatively determined by the UV spectrophotometer. The amount of Voriconazole remaining in the nail after permeation had been retrieved by milling test. The addition of thioglycolic acid, $5 \%$ improved the permeability of the drug by 0.7 as the enhancement factor. The formulation followed zero order kinetics and Korsmeyer- Peppas mechanism of drug release on analyzing on DDSolver. The voriconazole flux of $5592.1 \mu \mathrm{g} / \mathrm{cm} / \mathrm{min}$ and $596.75 \mu \mathrm{g} / \mathrm{cm} / \mathrm{min}$ had been observed at 24 and 48 hours aliquots respectively for the nail lacquer containing an enhancer. Significantly higher permeation rates were achieved in the presence of an enhancer. The inhibitory zones for the voriconazole transungual nail lacquer were evaluated by testing against the dermatophyte, Trichophyton rubrum on Sabouraud's Dextrose Agar. The effective zones of inhibitions suggested Voriconazole nail lacquer exhibiting moderate antifungal activity for the onchomycosis treatment.

Key words: Onchomycosis, Trichophyton rubrum, Thioglycolic acid, Zero order kinetics, Korsemeyer-Peppas model
\end{abstract}

\section{INTRODUCTION}

Over the years, the importance of nail permeability to topical therapeutics has been realized, primarily in relation to the treatment of onchomycosis; a fungal infection of fingernails and toenails which affects approximately $19 \%$ of the world population and is responsible for approximately $50 \%$ of all nail disorders ${ }^{1}$. Topical therapy is highly desirable because of its non-invasiveness, ability to target drugs to the site of action, minimizing systemic adverse effects and improving patient compliance. Recent advances in transungual delivery technology have led to the introduction of antifungal nail lacquers. Potent and latest second generation triazole antifungal agent Voriconazole with its lipophilic nature fulfils the requirement of an effective drug. Voriconazole [(2R,3S)-2-(2,4-difluorophenyl)-3-(5-fluoro-4-pyrimidinyl)1-(1H-1,2,4-triazol-1-yl)-2-butanol] is derived from the structure of fluconazole by replacement of one triazole moiety by a fluoropyrimidine group and alpha methylation is a new broad spectrum antifungal agent ${ }^{2}$. It is used in the treatment of superficial and systemic fungal infections caused by Aspergillus, Fusarium species, Cladophialophora bantiana, Rhizopus arrhizus, Scedosporium apiospermum, Wangiella dermatitidis, dimorphic fungi and Trichophyton rubrum, Trichophyton mentagrophytes \& Candida species ${ }^{3}$.

The human nail plate is a much more complex structure than it looks at the first sight. It protects the nail bed, the part directly under the nail plate filled with blood vessels; and the nail matrix, the part at the proximal ventral surface of the nail responsible for cell's proliferartion and nail growth. Although thin, the nail plate has 80-90 layers of dead cells and mainly consists of keratins; $4 / 5$ is hard hair-type keratin and $1 / 5$ is soft skin-type keratin ${ }^{1}$; and is mainly associated with stem cell function ${ }^{4}$

The present work investigated the permeability of the antifungal drug, Voriconazole through the human nail plate from the nail lacquer formulation with and without a penetration enhancer, thioglycolic acid. The relation between the Voriconazole penetrated in to the nail, which forms a reservoir in the nail was investigated after the permeation experiment followed by the drug release kinetics and mechanisms. Finally the formulations were discussed in respect to their enhancement factors by estimating the zone of inhibition against the dermatophyte, Trichophyton rubrum.

\section{MATERIALS AND METHODS}

\section{Materials}

Voriconazole was obtained as a gift sample from Cipla Pvt. Ltd., Mumbai, India; which was chosen as the model antifungal agent. Cellulose nitrate RS, thioglycolic acid, potassium dihydrogen phosphate, and disodium hydrogen phosphate were purchased from Qualigens Fischer Scientific. Aqueous solutions were prepared using deionised water supplied by Millipore water purification system, France. The $\mathrm{pH}$ was analyzed using the $\mathrm{pH}$ meter (Lab India) 
and the permeation aliquots were quantitated using UV spectrophotometer lambda-25 (Perkin Elmer).

\section{Collection, evaluation and characterization of nail samples}

\section{Collection of nail samples}

Human cadaver nail samples were collected from human corpuses at the Mahatma Gandhi Missions Medical Centre and Research Institute, Aurangabad, Maharashtra, India and Rajiv Gandhi Medical College \& Chhatrapati Shivaji Maharaj Hospital Mumbai, Maharashtra. Two week old corpuses, which have been used in anatomy courses, were filled with $3 \%$ solution of formaldehyde. Nails were wet, mostly soft, and strongly bound to the surrounding tissue. By removing the skin, nail edges were liberated and then the nail bed was pressed down along the whole nail plate by easily placing forceps between the ventral nail plate and the nail bed, moving in the direction of nail matrix. Using claws, the nail plate was uprooted. This technique ensured fast collection of the whole nail plates, without breaking them. Only healthy nail plates were used in this study. It is suggested that the permeability through healthy and fungal nail plates is not significantly different. Thus, the fungal nail permeability can be estimated from healthy nail permeability data ${ }^{1}$.

\section{Evaluation of nail samples}

Since nail samples were from two week old corpuses, possible interaction of formaldehyde might have occurred. The nail plates were washed at room temperature using clean mild liquid detergent containing sodium lauryl sulphate (SLS) and distilled water. These were further dried to constant weight at $45^{\circ} \mathrm{C}$. For each nail sample, the dry weight and thickness were measured at three points with a vernier caliper [Mitutoyo] and averaged for each nail ${ }^{2}$.

\section{Characterization of nail samples}

Nail samples were left over night for equilibration at open air and room temperature. On the next day, weight of the whole nail and thickness (Vernier caliper, Mitutoyo) were noted. Samples were placed in PBS solution for $60 \mathrm{~min}$, in order to achieve maximal hydration. The wet nails were mounted in Franz diffusion cells containing PBS in the acceptor chamber.

\section{Preparation and characterization of the formulations}

The formulations were made by the standard protocols for the nail lacquer formulation. The solvent system of isopropyl alcohol, butyl acetate, ethyl acetate and n-butyl alcohol was chosen with Cellulose nitrate RS as the film forming agent. Five different formulation batches containing differing concentration of Cellulose nitrate RS [5\%, 10\%, 15\%, 20\% and 25\%] were made and evaluated for $\mathrm{pH}$ ( $\mathrm{pH}$ meter, Lab India), viscosity, hardness, drying rate, water resistance and stability analysis (Stability Chamber, Thermolab). The selected formulation batches were assessed for increase in the penetration by adding thioglycolic acid (5\%) in the formulation, and one extra batch devoid of it ${ }^{5-7}$.

\section{Permeation studies}

Permeation studies were performed using Franz diffusion cells with a diffusion area of $0.785 \mathrm{~cm}^{2}$. The acceptor chamber was filled with $15 \mathrm{ml}$ of Phosphate buffer saline [pH 7.4] solution and constantly stirred with a $3 \mathrm{~mm}$ (c) 2011, JDDT. All Rights Reserved magnetic stir bar at $400 \mathrm{rpm}$. The water jacket retained a temperature of $32 \pm 1^{\circ} \mathrm{C}$. The formulation $(400 \mu \mathrm{l})$ was applied on the nail surface. Intermittent samples of $4 \mathrm{ml}$ were drawn from the receiver compartment till $72 \mathrm{~h}$ and the acceptor chamber was refilled each time with equal amount of Phosphate buffer saline solution, which was kept in a dark place at room temperature. An occlusive effect was attained throughout the experiment and the whole set up was protected from daily light by cardboard. The amount of Voriconazole in the collected samples was determined by UV spectrophotometer at $254 \mathrm{~nm}$. The flux is defined as the amount of drug permeated through the nail per time and unit area; which was extrapolated to account for the permeability coefficient $(\mathrm{cm} / \mathrm{s})$. The enhancement factor was determined representing as the ratio of permeability coefficient of the formulation containing an enhancer to the permeability coefficient of the formulation devoid of an enhancer ${ }^{2,5,8}$.

\section{Milling test}

After the permeation experiment, the nails were milled in order to detect the amount of Voriconazole remained in the film and nail plate. The milling test was performed by pulverizing the mounted nail plate using a filer [Soligen, Germany]. After an equilibration time at room temperature, the pulverized nail was suspended in the phosphate buffer saline ( $\mathrm{pH} 7.5)$ and was shaken for $5 \mathrm{~min}{ }^{1,7,8}$. Immediately after centrifugation for $5 \mathrm{~min}$ at $10,000 \mathrm{rpm}$, supernatants were diluted with acetonitrile and measured by UV spectrophotometer at $254 \mathrm{~nm}$.

\section{Antifungal susceptibility test}

\section{Preparation of Sabouraud dextrose agar (SDA)}

Briefly, $23.5 \mathrm{~g}$ of the powdered SDA base with Emmon's modification [Himedia Lab Pvt. Ltd.] was suspended in 500 $\mathrm{ml}$ of distilled water. The mixture was then heated to boiling point whilst stirring to dissolve the powdered agar completely. The agar solution was then sterilised in an autoclave for 15 minutes at $121^{\circ} \mathrm{C}$ [15 lbs]. The $\mathrm{pH}$ was maintained at $7 \pm 0.2$.

\section{Inoculum suspension for susceptibility testing}

The sterilized SDA was poured in to sterile tubes and slants were made for subculturing. After the growth period of $7-8$ days, the T.rubrum species were isolated and each isolate was suspended in $5 \mathrm{ml}$ of sterile distilled water. For the Kirby Bauer's disk diffusion method, an inoculum concentration of $1 \times 10^{6}-5 \times 10^{6}$ colony forming units $/ \mathrm{ml}[\mathrm{cfu} / \mathrm{ml}]$ of the Trichophyton rubrum dermatophyte were spread on the sterile plates ${ }^{9}$.

\section{Kirby Bauer's Disk diffusion test}

The assays were performed with the experimental method of Kirby Bauer in three replications. After inoculation, a circular paper disc of $5 \mathrm{~mm}$ was cut and sterilized. The discs were then applied with the selected optimized nail lacquer $(400 \mu \mathrm{l})$ and dried, and were placed on the surface of the SDA and pressed lightly to ensure good contact ${ }^{9}$. The plates were incubated at $27^{\circ} \mathrm{C}$ and the zones of inhibition were measured in millimeters using vernier caliper [Mitutoyo]. The interpretative range of standard zone was adopted from Ontengco et al. (1992). 


\section{RESULTS}

The Voriconazole on receival was characterized with respect to its melting point [Micro controller based melting point apparatus, Chemiline] which accounted in the range of $127^{\circ} \mathrm{C}-130^{\circ} \mathrm{C}$. The IR scan [Hydraulic pellet press KP, Kimaya Engg.] and wavelength analysis [UV spectrophotometer lambda-25, Perkin Elmer] revealed the strong presence of $-\mathrm{OH}$ bond around the frequency range of $3200 \mathrm{~cm}^{-1}$ while that around $1351 \mathrm{~cm}^{-1}$ depicted the presence of C-N stretch which can be seen in the chemical structure of Voriconazole. The peaks around the frequency range of 3000 $\mathrm{cm}^{-1}$ showed the presence of aromatic rings and the wavelength of $254 \mathrm{~nm}$ provided the Voriconazole peak.

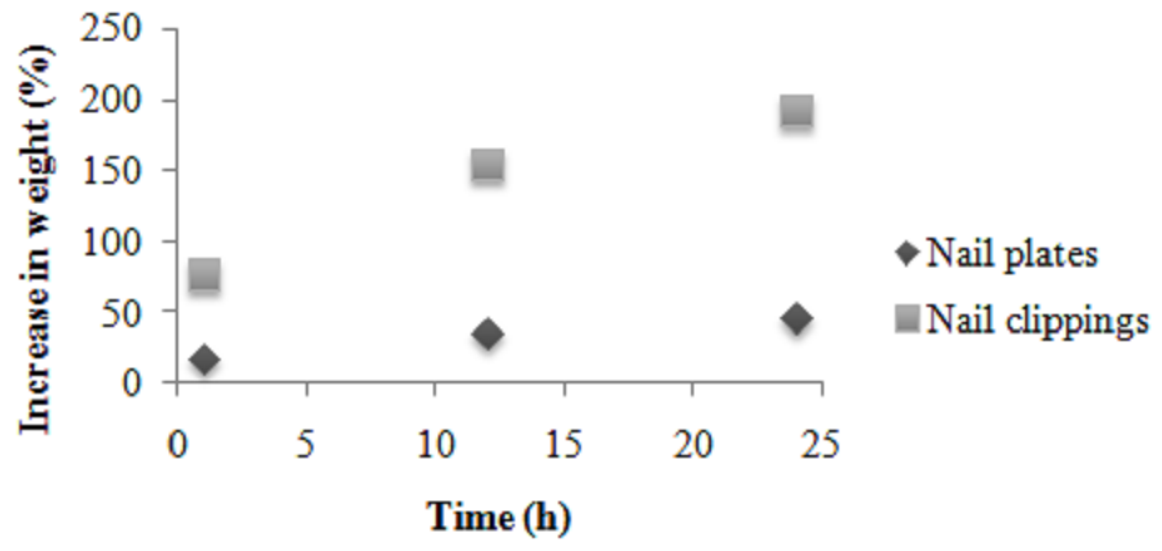

Figure 1 The effect of hydration on the human nail plates and nail clippings

The nail plates as well as the nail clippings [fig. 1] were found to equally accept water in the hydration studies 1,10 . The average weight increase of ten nail plates after 24 hours was determined to be $45.84 \pm 1.24 \%$. The difference in weight between wet, i.e., for $60 \mathrm{~min}$ immersed nails in PBS, and dry nails was expressed as percentage of weight increase. After the immersion time of $1 \mathrm{~h}$, detected weight increase was found to be $18.34 \%$ with a standard deviation of $\pm 0.50 \%$. The weight of the dry nails before and 24 hours after the experiments were also compared. Slight increase of weight was detected in dry samples measured after the permeation studies, with an average of $1.25 \%$. All the formulations showed $\mathrm{pH}$ values in the range of $5-7.5$ and revealed Newtonian flow behavior [Brookefield DV-II + Pro viscometer] except F1 and F2 formulation batches ${ }^{8}$ as shown in the fig. 2. The formulations were found to be stable till thirty days at $40^{\circ} \mathrm{C}, 75 \% \mathrm{RH}$ [Stability chamber Th400G, Thermolab].

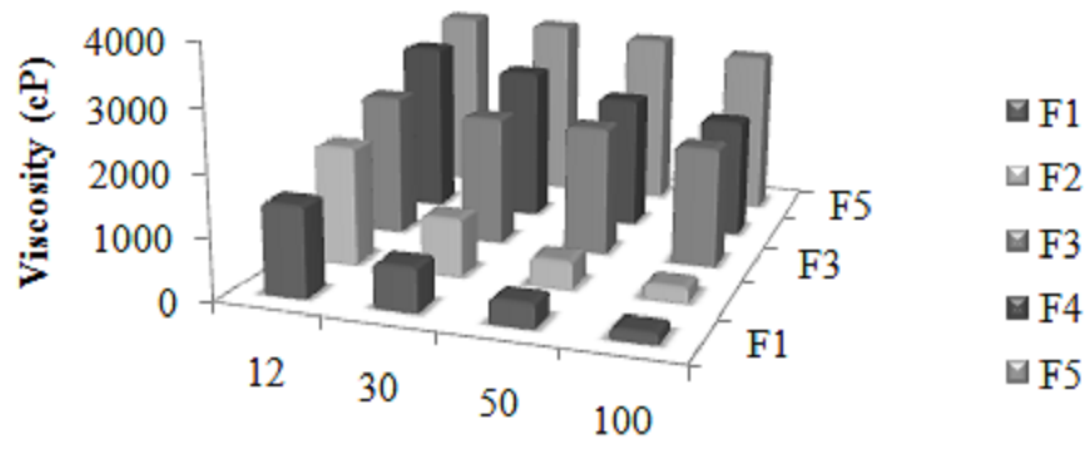

\section{Shear (rpm)}

Figure 2 The effect of shear stress on the viscosity of the nail lacquer

\section{formulations; F1, F2, F3, F4 and F5}

The Trichophyton rubrum seeded SDA plates showed the zones of inhibitions for the Voriconazole nail lacquer when compared with the control nail lacquer formulation containing the nail lacquer base only. The lacquer paper discs of $5 \mathrm{~mm}$ applied with $400 \mu \mathrm{l}(8 \mathrm{mg})$ of the formulation inhibited the growth of the Trichophyton rubrum colonies while the growth was seen around the control disc. The (c) 2011, JDDT. All Rights Reserved observations showed the zone of inhibition of about $14 \mathrm{~mm}$ and $16 \mathrm{~mm}$ for the Voriconazole nail lacquer without an enhancer and one with an enhancer respectively. No zones of inhibition were seen for the control disc which contained the nail lacquer base only. 
The nail permeation decrease after 48 hours can be attributed to the reapplication of the lacquer containing the Voriconazole and thus the fungal dermatophyte inhibitory activity can be achieved. The reapplication of the formulation would maintain the resistivity to these species as the $400 \mu \mathrm{l}$ of the disc containing $8 \mathrm{mg}$ of the Voriconazole gave moderate zones according to Segismundo et al., 2010.

\section{DISCUSSION}

Based on the preliminary parameters [Table 1], the formulation 1 and formulation 2 were rejected for the permeation studies as they lacked the Newtonian viscosity.

Table I Preliminary evaluation parameters for the five nail lacquer formulation batches containing varying concentration of Cellulose nitrate RS

\begin{tabular}{|c|c|c|c|c|c|}
\hline $\begin{array}{l}\text { Formulations } \\
\text { Parameters }\end{array}$ & Fl & F2 & F3 & F4 & F5 \\
\hline Color, clarity & \multicolumn{5}{|c|}{ Light pale yellow, clear } \\
\hline $\begin{array}{c}\text { Non-volatile } \\
\text { content }\end{array}$ & \multicolumn{5}{|c|}{$95.91 \%-97.91 \%$} \\
\hline Drying rate & \multicolumn{5}{|c|}{$87 \mathrm{~s}-111 \mathrm{~s}$} \\
\hline Smoothness & $\begin{array}{l}\text { Lumps at } \\
\text { intervals }\end{array}$ & $\begin{array}{l}\text { Smooth, lumps at } \\
\text { intervals }\end{array}$ & \multicolumn{3}{|c|}{ Smooth, evenly dispersed } \\
\hline Water resistance & $86.27 \%$ & $88.00 \%$ & $95.65 \%$ & $97.91 \%$ & $97.91 \%$ \\
\hline Hardness & Fair & Fair & $\begin{array}{l}\text { Very } \\
\text { good }\end{array}$ & Excellent & Excellent \\
\hline Viscosity & \multicolumn{2}{|c|}{ Considerable decrease in viscosity } & \multicolumn{3}{|c|}{$\begin{array}{l}\text { Slight decrease on shear } \\
\text { application }\end{array}$} \\
\hline Stability & \multicolumn{5}{|c|}{ Found to be stable at $40^{\circ} \mathrm{C}$ and $75 \% \mathrm{RH}$ till 30 days } \\
\hline
\end{tabular}

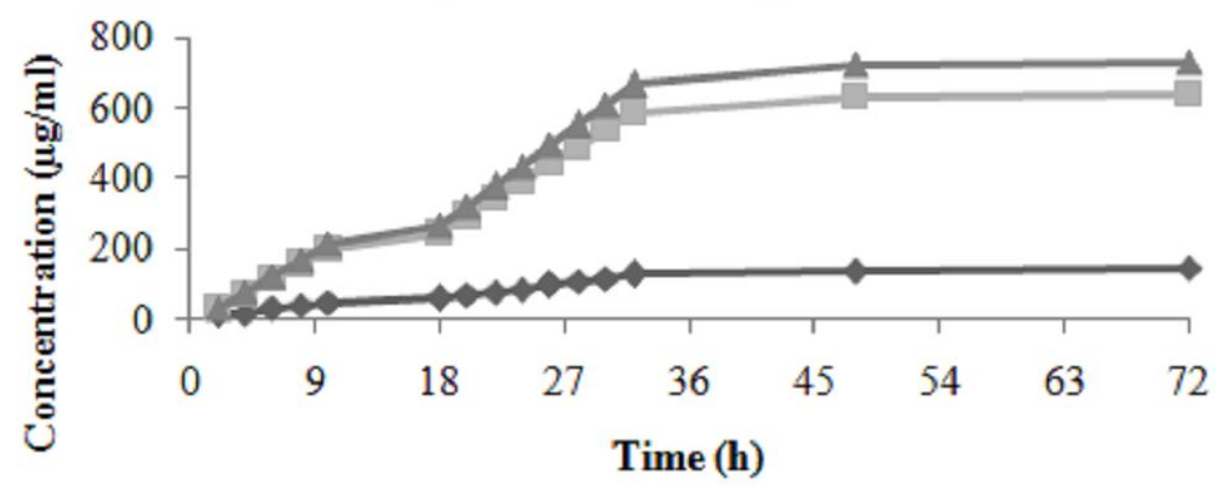

$\leadsto \mathrm{C} \rightarrow-\mathrm{VL} \leadsto \mathrm{VLe}$

Figure 3 The permeation profiles of the voriconazole nail lacquer 


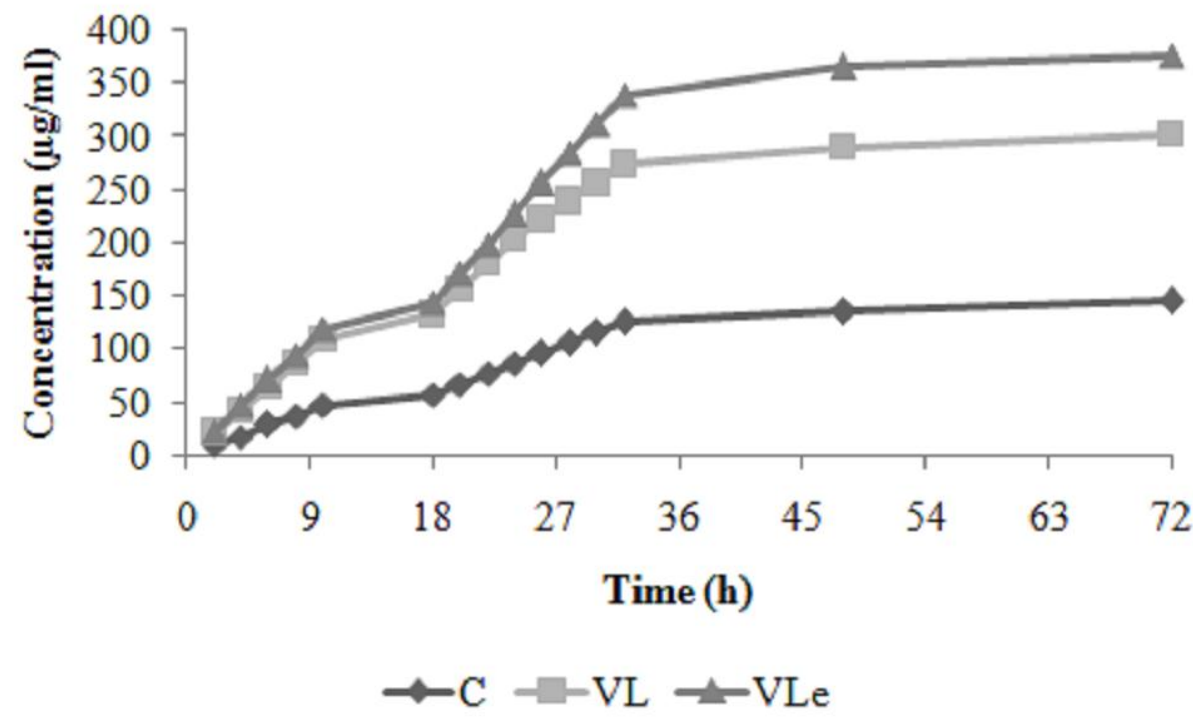

Figure 4 The permeation profiles of the voriconazole nail lacquer

formulation 4 containing $20 \%$ of Cellulose nitrate RS

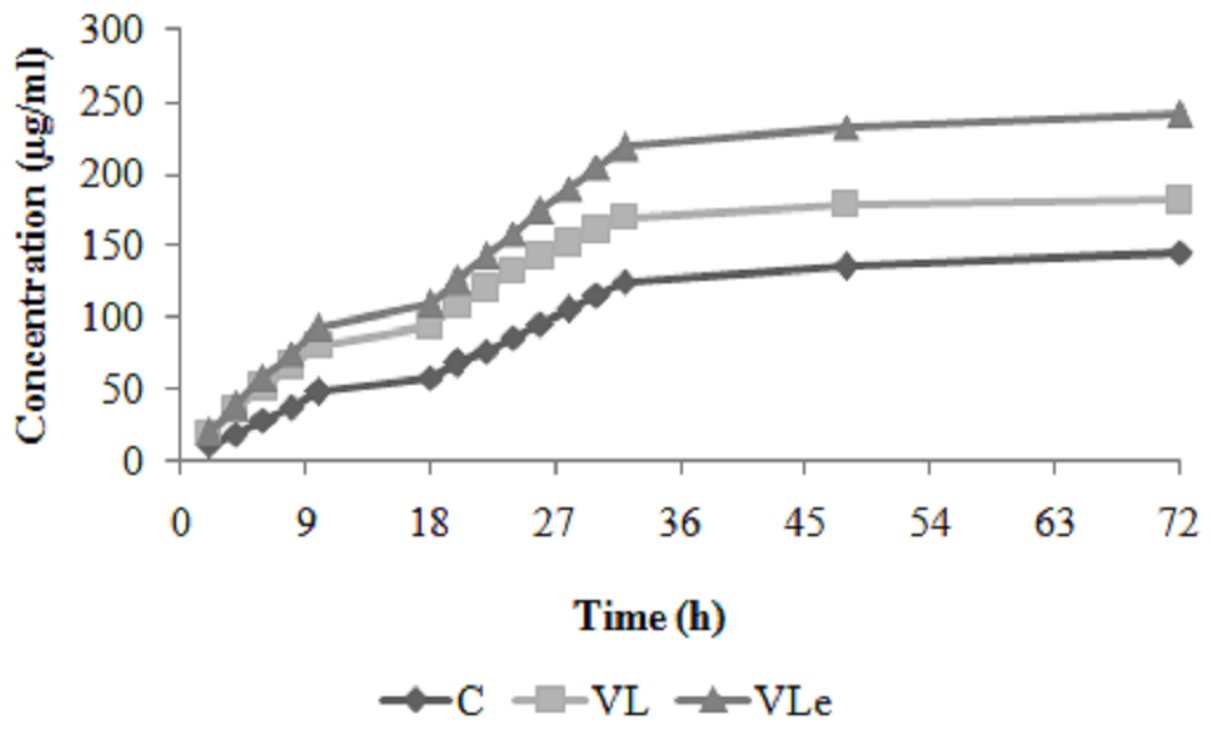

Figure 5 The permeation profiles of the voriconazole nail lacquer

\section{formulation 5 containing $25 \%$ of Cellulose nitrate RS}

The amount of Voriconazole permeated through the nail plate [fig. 3, fig. 4 and fig. 5] during ex vivo permeation study of the applied formulations shows the extent of nail penetration of Voriconazole by the penetration enhancer in the selected three formulations. Addition of thioglycolic acid improved the permeability of the Voriconazole to approximately about 0.7 as an enhancement factor in all the three formulations. Formulation 3 was found to release the drug with higher rate than the remaining two formulations [fig. 6]; and was optimized from the study.

The formulation 3 and formulation 4 showed less release of drug as compared to formulation 1 in the 72 hour permeation study. No correlation between permeability rate and nail weight was found before experiment, so it can be suggested that the main influence on the permeability rate was derived from the formulation. The effect of thioglycolic acid was attributed to its small molecular weight and damage caused on the keratin network and decrease in lipid content in the dorsal nail layer; this act which loosened the nail structure, allowing Voriconazole to penetrate easier. Thioglycolic acid showed the best enhancing potential and proved a good solvent for lipophilic drugs ${ }^{5,8}$. The higher levels of Voriconazole reservoirs were seen in the nails with the formulation devoid of an enhancer, thioglycolic acid. This was the same order in which the permeability rate decreased as shown in fig. 7. The logical conclusion was that if more Voriconazole permeated the nail, more Voriconazole was inside the nail after the experiment and thus one more proof for the decrease in the rate of permeation after a certain lag time. Correlation between enhancement factor and remaining Voriconazole in the nail is shown in the fig. 8. 


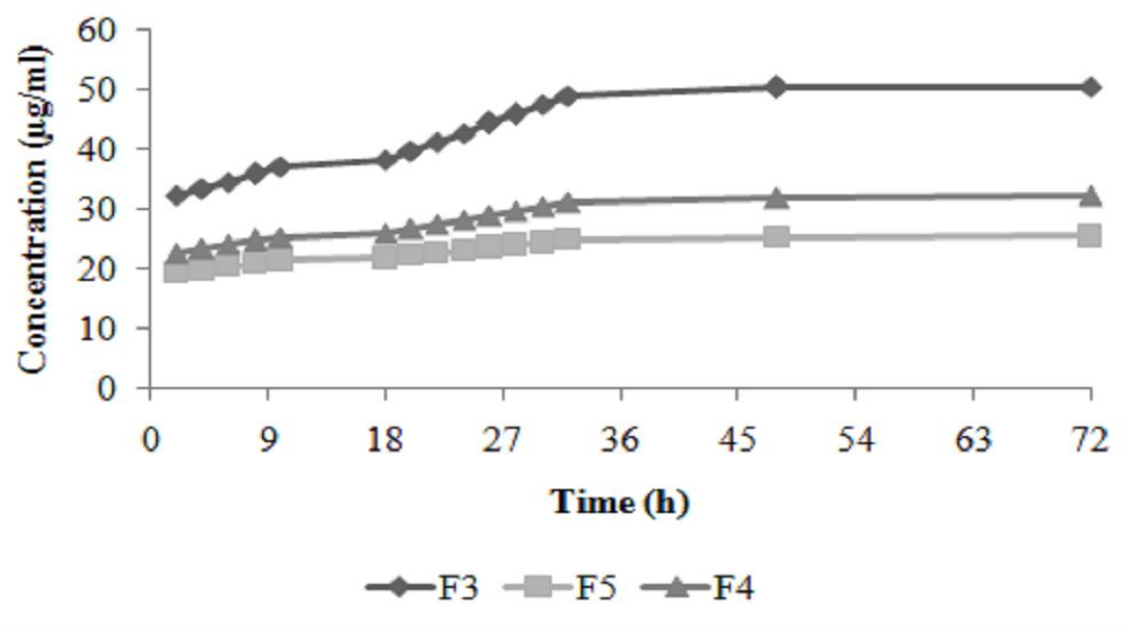

Figure 6 Comparison of the permeation profiles of the voriconazole nail lacquer formulations F3, F4 and F5 containing thioglycolic acid 5\% as penetration enhancer

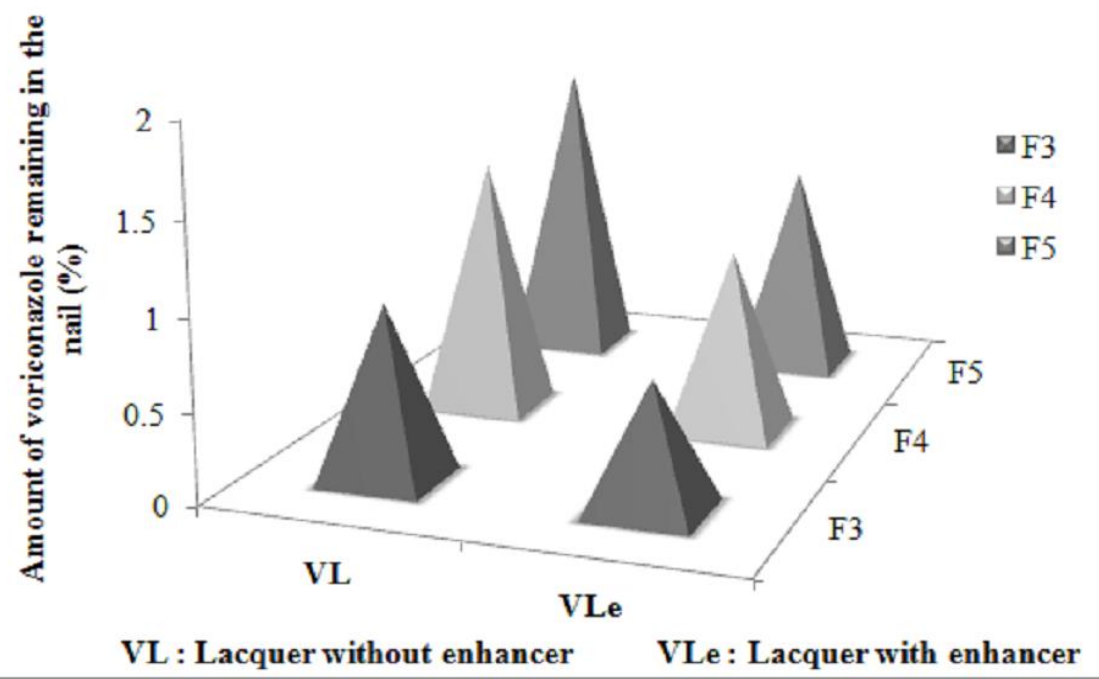

Figure 7 Profiles of the remaining amount of the nail lacquer present in the nail after the permeation studies of the three formulations, each with and without an enhancer

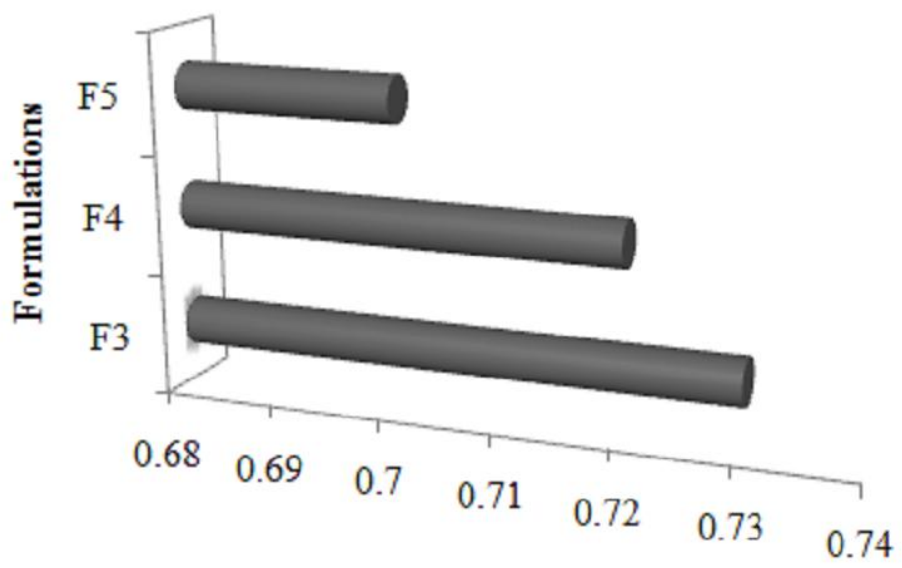

Enhancement factor

Figure 8 Enhancement factors calculated with respect to permeation study, where the formulation 3 shows the highest enhancement factor of 0.73 
The model selection criterias [MSC], correlation coefficient [R], Mean Square Error [MSE] and Akaike's Information Criteria [AIC] considered for the analysis of the release kinetics for the optimized formulation 3 containing $15 \%$ of
Cellulose nitrate RS showed the formulation 3 to follow Korsmeyer-Peppas model and zero order kinetics for both, the lacquer without an enhancer and with an enhancer [Table $2]$.

Table II Drug release mechanistic models and kinetics for the optimized formulation batch 3

\begin{tabular}{|c|c|c|c|c|c|c|c|c|c|c|c|c|}
\hline \multirow{2}{*}{ 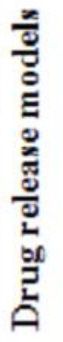 } & \multicolumn{4}{|c|}{ Control } & \multicolumn{4}{|c|}{ L } & \multicolumn{4}{|c|}{ Le } \\
\hline & $\stackrel{\frac{a}{\hat{b}}}{\underline{\underline{n}}}$ & $\frac{\sqrt[1]{2}}{2}$ & $\frac{U}{2}$ & $\underset{\psi}{\psi}$ & 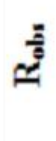 & 点 & $\underset{\Downarrow}{U}$ & 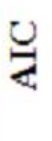 & $\stackrel{\frac{a}{\hat{b}}}{\underline{0}}$ & $\frac{\sqrt[1]{2}}{2}$ & $U_{2}$ & $\underset{\psi}{\longleftarrow}$ \\
\hline $\mathbf{N}$ & $\begin{array}{l}\bar{\circ} \\
\stackrel{\circ}{\circ}\end{array}$ & $\frac{\widetilde{N}}{\stackrel{\sim}{n}}$ & 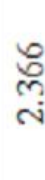 & $\begin{array}{l}\tilde{N} \\
\text { J } \\
\text { J }\end{array}$ & ڤ్ & 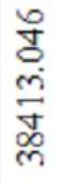 & 옹 & 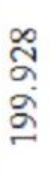 & ڤૂ & 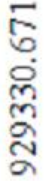 & $\begin{array}{l}\text { d } \\
\text { ?. }\end{array}$ & $\frac{a}{\sigma}$ \\
\hline Is & $\stackrel{\tilde{n}}{\stackrel{2}{c}}$ & 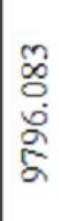 & স্তু & $\begin{array}{l}\stackrel{m}{\ddagger} \\
\stackrel{\Xi}{\Xi}\end{array}$ & g & 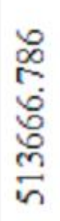 & $\begin{array}{l}\text { तै } \\
\text { : } \\
\dot{0}\end{array}$ & $\begin{array}{l}\approx \\
\infty \\
\infty \\
\infty \\
\sim \\
\sim\end{array}$ & लै & 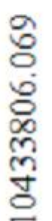 & $\begin{array}{l}\text { ñ } \\
\hat{o} \\
\dot{8}\end{array}$ & 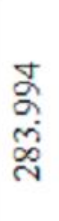 \\
\hline$=$ & $\stackrel{\text { J }}{\mathrm{g}}$ & $\begin{array}{l}m \\
\tilde{m} \\
\tilde{m} \\
\tilde{m} \\
m\end{array}$ & $\begin{array}{l}\stackrel{\circ}{\mathrm{S}} \\
\stackrel{-}{-}\end{array}$ & $\frac{m}{\stackrel{m}{g}}$ & $\frac{5}{\alpha}$ & $\begin{array}{l}\stackrel{0}{N} \\
\text { N } \\
\stackrel{\infty}{N}\end{array}$ & $\begin{array}{l}\frac{V}{\infty} \\
\infty \\
0\end{array}$ & $\frac{\stackrel{d}{d}}{\stackrel{N}{N}}$ & 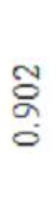 & 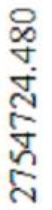 & $\begin{array}{l}\infty \\
\stackrel{\infty}{6} \\
\stackrel{0}{\circ}\end{array}$ & 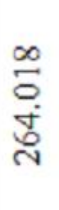 \\
\hline 1 & $\begin{array}{l}\stackrel{8}{\circ} \\
\stackrel{0}{\circ}\end{array}$ & $\begin{array}{l}n \\
m \\
0 \\
0\end{array}$ & 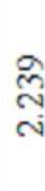 & $\begin{array}{l}\text { ma } \\
\text { d } \\
\text { In }\end{array}$ & $\frac{\text { v }}{2}$ & $\begin{array}{l}\infty \\
\infty \\
\stackrel{\infty}{\infty} \\
\stackrel{2}{ } \\
\stackrel{n}{n}\end{array}$ & $\begin{array}{l}\infty \\
\stackrel{\infty}{\longrightarrow}\end{array}$ & $\stackrel{2}{2}$ & 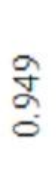 & 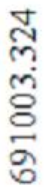 & $\overrightarrow{8}$ & $\frac{\widetilde{N}}{\stackrel{d}{d}}$ \\
\hline
\end{tabular}

\section{L: Lacquer without enhancer}

\section{AIC: Akaike's Information Criteria \\ $\mathrm{R}_{\text {obs }}$ : Correlation coefficient \\ F: First order release kinetics \\ $\mathrm{K}:$ Korsmeyer-peppas release kinetics}

The Voriconazole flux of the optimized lacquer with an enhancer was found to be $596.75 \mu \mathrm{g} / \mathrm{cm} / \mathrm{min}$ at an interval of $48^{\text {th }}$ hour, and provided the permeabilitiy coefficient of 58.56 $\mathrm{cm} / \mathrm{s}$. Similarly, the flux of lacquer without an enhancer was found to be $540.34 \mu \mathrm{g} / \mathrm{cm} / \mathrm{min}$ at the $48^{\text {th }}$ hour interval which gave $53.02 \mathrm{~cm} / \mathrm{s}$ as the permeability coefficient. Thus, the permeability was found to reduce after $48^{\text {th }}$ hour [fig. 9].

Avulsed human cadaver nails are a suitable model for the permeation studies. No formaldehyde was used in the nail formulation which keeps the formulation in pace with the Campaign for Safe Cosmetics [Safe Cosmetics Action

\section{Le: Lacquer with enhancer}

MSE: Mean Square Error

\section{Z: Zero order release kinetics \\ $\mathrm{H}$ : Higuchi release kinetics}

\section{MSC: Model Selection Criterion}

Network] and free of the toxic trio. Thioglycolic acid was seen to be an effective penetration enhancer for drug delivery through the nail plate. An effective enhancer is one, which can facilitate drug permeation through the keratinized nail membrane, could find application not only in the treatment of nail diseases, but also in the treatment of neighboring target sites, for example in the therapy of rheumatoid arthritis of hands and feet, if systemic circulation is reached. Thus, thioglycolic acid can even act as a periungual drug delivering agent when the target is the blood vessels in the nail bed. 
There is no efficient and approved topical formulation containing Voriconazole as an active drug in the market yet for the treatment of onchomycosis. However, a need for topical delivery of Voriconazole exists due to severe adverse effects of the oral therapy. Further, more research is needed to check the nail plate as a membrane in a deeper way. These insights will be helpful to develop therapies for other diseases through this alternative pathway; for inflammatory and infectitious diseases. Combining all the knowledge, expertise, and technical modalities the vision is that the human nail plate becomes one of the conventional routes for drug delivery.

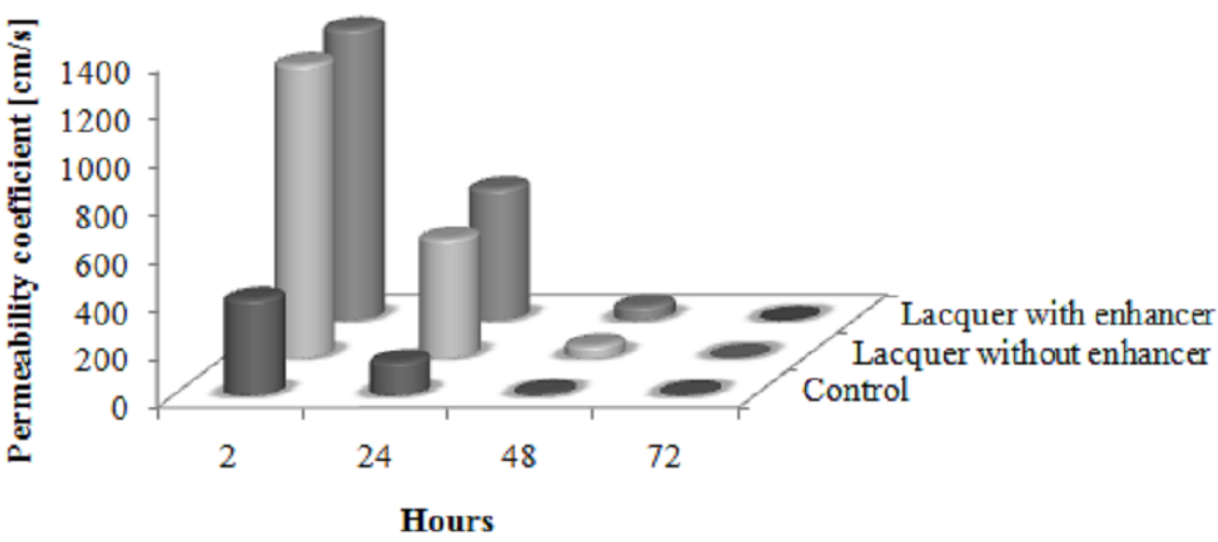

$\square$ Control $\square$ Lacquer without enhancer $\square$ Lacquer with enhancer

\section{Figure 9 Permeability coefficient of the optimized nail lacquer formulation 3}

A higher Voriconazole concentration and therefore higher concentration gradient has a positive influence on passive diffusion. The type of the pharmaceutical formulation and dosage form can contribute to therapeutic efficacy. The swelling behavior of nails is suggested to be less affected by the formulations with even an increased exposure over 24 hours. The evaluated enhancer, thioglycolic acid; facilitated the Voriconazole's permeation and penetration in to the nail plate. The stability tests showed that the formulations were stable. The optimized formulation was found to follow zero order kinetics and Korsmeyer-Peppas mechanism of drug release with lower mean square values which suggests that the concentration gradient would remain same even on increasing the Voriconazole bedding on the constant surface area. The model selection criterion [MSC], Mean square error $[\mathrm{MSE}]$, correlation coefficient $\left[\mathrm{R}_{\text {observed }}\right]$ and Akaike's Information Criterion [AIC] provided permeation profiles for the evaluation of goodness of fit of the model [DDSolver: An Add-In Program for modeling and comparison of drug permeation profiles].

\section{REFERENCES}

1. Vejnovic I, Simmler, L, Betz G. Investigation of different formulations for drug delivery through the nail plate. International Journal of Pharmaceutics. 2010; 386:185-194.

2. Gunt HB and Kasting GB. Effect of hydration on the permeation of ketoconazole through human nail plate in vitro. European Journal of pharmaceutical sciences. 2007; 32:254260.

3. Rubio MC, Ariz IR, Gil J, Benito J, Rezusta A. Potential fungicidal effect of Voriconazole against Candida spp. International Journal of Antimicrobial Agents, 2005;25:264 267.

4. Berker DA, Andre J, Baran R. Nail biology and nail science. International Journal of Cosmetic Science. 2007; 29:241-275.

(c) 2011, JDDT. All Rights Reserved
The Voriconazole nail lacquer was also found to be effective in inhibiting the growth of the nail fungi, Trichophyton rubrum and gave moderate zones of inhibition conferring for the reapplication of the formulation at intervals for sustaining the certain state of inhibition to cure the fungal infection. Therefore, formulations or treatments, which improve nail hydration, have potential to improve topical therapy for onchomycosis.

\section{ACKNOWLEDGEMENT}

We are grateful to Cipla Pvt. Ltd., Mumbai, India; Mahatma Gandhi Missions Medical Centre and Research Institute, Aurangabad, Maharashtra, India; Rajiv Gandhi Medical College \& Chhatrapati Shivaji Maharaj Hospital Mumbai, Maharashtra, India; and Microbial Type Culture Collection \& Gene Bank (MTCC), Institute of Microbial Technology, Chandigarh, India.

5. Kiran SR, Chandrashekhar B, Vishnu P, Prasad MVV. Ungual drug delivery systems of ketoconazole nail lacquer. Int J Appl Pharm. 2010; 4:17-19.

6. Natesan SK, Manavathu EK, Cutright JK, Chandrasekar PH. Efficacy of anidulafungin, caspofungin and fluconazole in the early phase of infection in a neutropenic murine invasive candidiasis model. International Journal of Antimicrobial Agents. 2010; 36:33-36.

7. Mithal BM and Saha RN. A handbook of cosmetics. Nail lacquer and removers. Vallabh Prakashan, $1^{\text {st }}$ edition, 2010:182-192.

8. Vejnovic I, Huonder C, Betz G. Permeation studies of novel terbinafine formulations containing hydrophobins through

ISSN: 2250-1177 
human nails in vitro. International journal of pharmaceutics. 2010; 397:67-76.

9. Morace $\mathrm{G}$ and Polonelli L. Voriconazole activity against clinical yeast isolates: a multicentre Italian study. International Journal of Antimicrobial Agents. 2010;26:247-253.

10. Elkeeb R, AliKhan A, Elkeeb L, Hui X, Maibach HI. Transungual drug delivery: Current status. International Journal of Pharmaceutics. 2010;384:1-8

11. Segismundo $\mathrm{AB}$, Florendo $\mathrm{PE}$, Pablico AR. In Vitro Antifungal Activity and Phytochemical Screening of Gouania javanica Miq. Leaves. UNP Research Journal. 2008;17:1-10.

12. Ontengco DC, Capal TV, Celia LH. A Manual on Extraction Procedures and Microbial Assay of Medicinal Plants. UNESCO, DOST, PSM. 1992:1. 